\title{
Vínculos entre el arte y el acto moral. Una revisión de las nociones de lo bueno y lo bello en Kant.
}

Links between art and moral act. A review about the notions of good and beauty in Kant.

DOI: 10.32870/sincronia.axxv.n79.6a21

\section{Alberto Cuauthémoc Mayorga Madrigal}

Departamento de Filosofía / Universidad de Guadalajara. (MÉXICO)

CE: c mayorgam@hotmail.com / ID ORCID: 0000-0002-4552-5754

Esta obra está bajo una Licencia Creative Commons Atribución-NoComercial 4.0 Internacional

Recibido: $20 / 09 / 2020$

Revisado: $18 / 10 / 2020$

Aprobado: $19 / 11 / 2020$

\section{RESUMEN}

La censura del arte es un fenómeno que permite la aproximación de dos disciplinas filosóficas: la ética y la estética. Con la censura, y en ocasiones también con el elogio de la obra de arte se manifiestan vínculos entre valoraciones con orientaciones distintas, haciéndose patentes fenómenos comunes de índole intelectual referentes condiciones de autonomía, valoración, Intención, abstracción y asimilación. Con este análisis pretendemos indagar, siguiendo a Kant, algunos aspectos y nociones fundamentales que vinculan al arte y la moral en lo que se refiere al origen y naturaleza de los juicios (ético y estético) y los fenómenos (obra de arte y acto moral).

Palabras Clave: Belleza. Bien. Juicio. Libertad. Razón.

\section{ABSTRACT}

Censorship of art implies the connection between Ethics and Aesthethics: different kind of valuations and orientations in artistic work, such as censorship as well as compliment, enlightens usual phenomena concerning autonomy, valuation, volition, abstraction and assimilation conditions of it. Therefore, our aim is to explore some fundamental Kantian features between morals and arts concerning the judgment, as well as its results (i.e. piece of art and moral act). 
Keywords: Beauty. Good. Trials. Freedom. Reason.

\section{Introducción}

Para 27 de febrero del 2015 se había programado la inauguración de una exposición del artista Austriaco Hermann Nitsch en el museo Jumex en la Ciudad de México. Pero tres semanas antes la presentación fue cancelada. La razón de dicha suspensión fue atribuida principalmente a la presión que ejercieron diferentes sectores de la sociedad, especialmente defensores de los derechos de los animales que consideraron incorrecto (desde su punto de vista moral) el trabajo de Nitsch. (Ortuño, 2015), (Ballesteros, 2015), (Burnett, 2015).

\section{Respecto a la suspensión el artista declaró al periódico Excelsior:}

Nunca me había pasado que una exposición se cancelara. Por supuesto había debates sobre mis actuaciones con base en la blasfemia y, en los últimos años, sobre todo derechos de los animales. La cancelación de la exposición me deja muy, muy triste. (Nitsch, 2015).

Hermann Nitsch es un artista austriaco identificado con el accionismo vienes. Su obra se manifiesta a través de una peculiar combinación de teatro, danza, música y pintura, con la integración de diversas manifestaciones rituales religiosos y paganos. Su obra ha causado el repudio de algunos sectores de la sociedad por la inclusión de escenas orgiásticas en donde se utilizan animales muertos y baños de sangre, en su intención de representar la fuerza del ritualismo.

De acuerdo con Laura de la Colina del grupo de investigación mitocracia de la facultad de Bellas Artes de la Universidad Complutense de Madrid:

En la obra de $\mathrm{H}$. Nitsch, durante su estancia en el accionismo vienes, aparecen elementos tales como la sangre, vísceras o cadáveres de corderos; pero siempre vinculados con la religión, de hecho, el artista se caracterizará por el uso de casullas que vestirá durante las acciones, a modo de maestro de ceremonias. (De la Colina, 2015, p. 10). 
Más adelante afirma: "Probablemente, el contenido más violento de sus acciones se ponga de manifiesto desde su actitud rebelde, en el que llevan al límite de manera ejemplar la construcción social humana, alterando los tradicionales valores morales" (10).

En la historia podríamos ejemplificar cientos de situaciones, especialmente en los casos de censura, que vinculan de una manera clara el arte y la moral, como en el caso del accionismo vienes. Lo anterior, entreteje a dos disciplinas filosóficas: la ética y la estética y nos mueve a plantearnos algunas preguntas: ¿El arte debiera atender pautas de la moralidad? ¿cuál es el vínculo que existe entre arte y moral?

Independientemente de la opinión que podamos tener sobre esta u otras manifestaciones artísticas u objetos estéticos, podemos iniciar nuestro análisis, planteando algunas nociones que nos podrían ayudar a la comprensión de este encuentro.

a) Sobre su naturaleza. La belleza y el bien son considerados como juicios que emitimos sobre objetos o acciones y que requieren de la interacción entre la mente del sujeto y cualidades de un fenómeno. El fenómeno respectivo puede ser o la obra de arte o una acción moral. Sin un sujeto que ejerza una valoración estética o ética sobre un fenómeno en cuestión, no hay bien o belleza.

b) Sobre su génesis. Respecto al origen del fundamento de los juicios éticos o estéticos hay dos posibilidades: a) las nociones ideales (bien y belleza) son independientes del sujeto o b) son adquiridas a través de procesos de interacción social o motivos de índole psicológico.

c) Sobre su posibilidad de conocimiento. El juicio de verdad que hacemos sobre un objeto se sustenta en el análisis que de los juicios sobre un objeto en cuestión se presenten. En este sentido ante la pregunta de si podemos saber si "la obra de Nitsch es mala" (en sentido moral) o "la obra de Nitsch es bella", implica dos posibilidades que podemos rastrear en función de si génesis y desarrollo: 1. Ante el supuesto de que las nociones generales de la apreciación estética y la moral tienen una génesis psicológica o cultural, se desprendería la imposibilidad de tener certezas sobre el juicio correcto o incorrecto; en otra palabras, estaríamos ante los criterios generales del relativismo y subjetivismo moral y estético que conducen a un escepticismo axiológico. De lo anterior se desprende que carecemos de un criterio sólido para censurar el arte. Por el contrario, si los juicios 
éticos y estéticos son independientes de las motivaciones subjetivas o la cultura, entonces podríamos rastrear un criterio que nos permita juzgar la verdad y la validez de las expresiones que sobre las obras arte y actos morales se emiten.

En función de la pretensión de encontrar criterios para la fundamentación de nuestros juicios acerca del bien, la belleza y sus vínculos, podríamos reconocer un criterio de análisis atendiendo algunas de las reflexiones que, sobre teoría del arte, escribiera Immanuel Kant.

La obra filosófica de Kant fue escrita durante el siglo XVIII. Las obras que de manera más sistemática enmarcan su pensamiento son: La crítica de la razón pura, cuyo objetivo consiste en examinar los límites y posibilidades del conocimiento; la crítica de la razón práctica, cuyo objetivo es la ética y la crítica del juicio que tiene como temas centrales la estética y la teología. Entre sus pretensiones más destacadas cabe señalar:

a) Poner de manifiesto el carácter activo de la razón en sus funciones cognitivas.

b) Identificar los límites y el alcance de las funciones cognitivas de la razón.

c) Poner de manifiesto el papel de la razón en el dominio práctico de la moral;

d) Precisar cuál es la aportación de la razón en el dominio de las cuestiones últimas de índole metafísico - religiosa, como la inmortalidad del alma y la existencia.

Para avanzar en nuestra indagación me permitiré reseñar algunos aspectos que nos ayudarían a comprender la noción de la belleza y del bien, de acuerdo con Kant, apoyándome principalmente en la Crítica de la razón práctica, la metafísica de las costumbres y la Crítica del juicio o del discernimiento, para, posteriormente, exponer mi posición sobre los vínculos entre la noción de belleza y bien en el pensamiento kantiano que, en términos generales, consiste en mostrar que en ambos casos hay una pretensión de superar el relativismo ético y estético y, mostrar que, para una comprensión pura de la belleza y el bien, el punto de partida es la noción de libertad.

En parágrafo 43 de la crítica del Juicio Kant expone su noción de libertad en el arte en los siguientes términos: “...debería llamarse arte a la producción mediante libertad, esto es, mediante una voluntad libre que pone a la razón como fundamento de sus acciones" (Kant, 2003, §43. pp. 
269-269). Esta noción no ofrece contradicciones ante otros pasajes en que Kant hace referencia a la libertady, como intentaré mostrar más adelante, resulta pertinente tanto para exponer los criterios de la producción del arte, como los criterios para la realización de la moral.

Una primera aproximación a nuestras indagaciones nos permitiría afirmar que la noción de libertad, que se hace patente una acción reflexiva del sujeto, se establece un primer vínculo entre arte y moral, que, como hemos mencionado, se materializan a través de obras o acciones.

\section{El bien.}

Con la crítica de la razón práctica Kant pretende establecer un discernimiento de aceptación universal fundado en la razón que nos permita reconocer un criterio general para el juicio moral y, soportados en este principio, superar el escepticismo al que irremediablemente conducen tanto el subjetivismo como el historicismo.

En la disposición por establecer las bases racionales de la moral, Kant tomará distancia de la tradición, de la moral empírica, y de la moral teológica. El distanciamiento tiene sentido si consideramos que entre pueblos distintos existen tradiciones o normas morales diversas: lo que para un pueblo es un vicio, para otro puede ser una virtud. Un caso similar lo encontramos en la moral empírica, donde, apelando a las investigaciones en ética práctica, se puede afirmar que mientras que el máximo bien para la mayoría de los humanos, es vivir, habrá algunas situaciones en donde el mayor bien es morir. Respecto a la moral teológica, prevalecen los mismos principios que en la tradición, pero además con la negación de la racionalidad humana al establecer un principio supra-humano como criterio de normatividad moral. Por lo anterior, la pureza de la moral no puede encontrarse en las prácticas históricas, ideológicas o subjetivas, sino en un criterio racional, y este lo encuentra en las nociones del deber y la libertad.

El deber es una noción intelectual identificada con lo necesario y no siempre vinculada con los fenómenos contingentes; es una noción que tiene su punto de partida en la razón pura. Por su parte, la libertad, vinculada con la definición que presentaba anteriormente, se encuentra desligada del determinismo causal en tanto que tiene su punto de partida en la razón. De esta manera 
libertad y deber encuentran su manifestación en las acciones o en los actos morales y, tanto la libertad como el deber, forman parte de la esencia racional del hombre.

De la libertad y el deber, Kant, en los Fundamentos para una metafísica de las costumbres, deriva las máximas que dan fundamento al juicio sobre el bien o el mal, soportadas sobre la ley general:

1. “Obra sólo de forma que puedas desear que la máxima de tu acción se convierta en una ley universal..."

2. “Obra como si, por medio de tus máximas, fueras siempre un miembro legislador en un reino universal de los fines".

3. "Obra de tal modo que uses la humanidad, tanto en tu persona como en la de cualquier otro, siempre como un fin, y nunca sólo como un medio". (Kant, 2012, pp. 151-154).

Dado que a partir de criterios empíricos y contingentes no podemos establecer principios consistentes para el establecimiento del juicio moral, Kant apela a la razón, como criterio de universalidad para su fundamentación.

\section{La belleza.}

Como hemos señalado una de las pretensiones centrales del sistema Kantiano tiene que ver con la justificación de los juicios sobre la naturaleza y las acciones. En esta tarea el punto de partida lo encuentra en la razón pura o, dicho de otra manera, en la formulación de juicios desvinculados de la contingencia de los contenidos empíricos. En el caso del juicio sobre lo bello el proceder no contradice lo establecido anteriormente, pero sí recure a un proceder diferente en función de la naturaleza de los contenidos de los juicios y los objetos estéticos.

El juicio de gusto es el propio de la apreciación de la belleza y presenta un carácter peculiar al ser observado desde el punto de vista de cuatro categorías que regulan el funcionamiento del entendimiento: 
Cualidad: el juicio de gusto es desinteresado, no surge la idea de poseer el objeto, hasta nos despreocupamos de su existencia real, el agrado está en la pura representación y esto se distingue de lo bueno y lo placentero.

Cantidad: lo bello nos agrada universalmente sin concepto, se distingue de lo bueno y lo placentero.

Relación: lo bello como forma final de un objeto sin representación.

Causalidad: con relación a un objeto, lo bello no gusta porque satisfaga y así se distingue una vez más de lo agradable y lo bueno (Plázola, 2007, p. 103).

Lo bello nos causa placer, es la imaginación, es entendimiento sin ningún interés. No se subordina a las formas sensibles de la especie humana, sino que, se toma conciencia de ser necesario frente a ellas, al estar libre de su influjo, pues las facultades del entendimiento sobrepasan en toda medida la contingencia de los sentidos.

En la estética nos encontramos frente a tres objetos de análisis: el creador del arte, el espectador del arte y el objeto estético. El criterio de las categorías del juicio estético cobra sentido en los tres objetos. Respecto al creador en tanto productor de lo bello, respecto al objeto como entidad sobre la que se establece el juicio de gusto y respecto al espectador como ente con capacidad de juicio de gusto.

\section{El vínculo entre belleza y bien}

Respecto a las pretensiones de Kant de superar el carácter contingente de los juicios sobre la moral o la estética, el punto de partida es básicamente formal, sin ser situado exclusivamente en una formalización desligada de lo real ya que, su punto de concretización, se da en el acto moral, la expectación del objeto bello o la realización del arte.

En ambas nociones un criterio común formal es la noción de libertad en tanto que "voluntad que pone razón a la base de su actividad"; y, con esta noción, se logra emparentar el vínculo en diferentes sentidos. Me permitiré profundizar en este punto haciendo referencia a los parágrafos 43 a 45 de la Crítica del Juicio: 
a) La libertad se presenta como un principio moral que humaniza en tanto que sólo el arte y el acto moral son producto de la libertad, en tanto que implican la manifestación de una voluntad con el respaldo de la racionalidad.

b) Se establece una distancia respecto a la naturaleza. Ciertamente en la naturaleza podemos reconocer espectáculos bellos, pero no arte y, respecto a la moral, una acción sólo será comprendida como tal en tanto que es resultado de las nociones humanas del deber y la libertad.

c) Kant distingue el arte bello de otro tipo de manifestaciones también llamadas artísticas en función de su génesis: esto es: si realmente son o no producto de la libertad. Lo mismo podríamos decir del acto moral. Así, un atardecer puede recibir el calificativo de bello o una mascota fiel puede ser descrita como buena, pero, en ninguno de los casos, son ni artísticas ni morales respectivamente.

\section{Tipos de manifestaciones estéticas y analogías con el acto moral}

Entre los parágrafos 43 y 44 de la crítica del juicio o del discernimiento, Kant ofrece un conjunto de manifestaciones consideradas como manifestaciones artísticas, pero que, en el análisis de su génesis y materialización, distarían de ser consideradas como arte bello.

Arte mecánico:

Cuando el arte, adecuado al conocimiento de un objeto posible, para realizarlo realmente, cumple las acciones exigibles a este respecto, es entonces un arte mecánico; pero si tiene como intención inmediata el sentimiento del placer, se denomina entonces arte estético. (Kant, 2003, pp. 371).

Tal es el caso de aquellas producciones que, pueden resultar agradables a la sensibilidad, pero resultan de una actividad monótona y repetitiva que ha dejado de lado la creación producto de la libertad y reproduce en serie con escaza participación de la razón. Por analogía, una acción que se realiza reproduciendo las costumbres, no podría ser considerada, propiamente, un acto moral. 


\section{Arte mercenario.}

El arte también se diferencia de la artesanía; el primero se denomina libre, el segundo también podría denominarse arte retribuido. Al primero se le ve como si pudiera resultar mal (o bien) teleológicamente sólo como juego, esto es, como ocupación agradable por sí misma. Al segundo como trabajo, esto es, como ocupación por sí misma desagradable (fatigosa) y que sólo es atractiva por su efecto (por ejemplo, la retribución) y en esta medida como algo que puede imponerse coercitivamente. (270)

También, en sentido análogo con la moral, aquellos actos que son realizados por presión externa o en con la finalidad de obtener un benéfico económico, a pesar de generar un benéfico al destinatario del acto, no puede propiamente ser definido como un acto moral en tanto que se hace evidente la ausencia de la autonomía y el deber.

\section{Arte agradable:}

Las artes agradables son aquellas referidas sólo al goce. Tales son todos los estímulos que la sociedad puede satisfacer en torno a una mesa: como referir historias de manera entretenida, entusiasman a la sociedad con una conversación franca o vivaz, disponerla mediante chanzas y risas a un cierto tono de alegría, donde, como suele decirse, en un banquete puede parlotearse sin que nadie se haga responsable de lo que dice, porque sólo se apunta a la distracción momentánea, no a una materia permanente para la reflexión o para la repetición. (271)

En correspondencia con las acciones, aquellas que tiene por fin sólo la satisfacción de placeres individuales o colectivos, sin atención al deber, no constituyen propiamente un acto moral.

Finalmente, será posible hacer una analogía del acto moral con el arte bello en tanto que este último es definido en los siguientes términos:

El arte bello, por el contrario, es una forma de representación que es teleológica por sí misma y que a pesar de carecer de fin, fomenta, sin embargo, la cultura de las capacidades de ánimo para una comunicación sociable.

La comunicabilidad universal de un placer ya lleva consigo en su concepto el que no deba ser un placer del goce a partir de la mera sensación, sino de la reflexión. Así, el arte 
estético, en tanto que arte bello, es tal que posee como patrón de medida el discernimie nto reflexionante y no la sensación de los sentidos. (272)

En este tenor, tanto el acto moral puro como el arte bello, se corresponden al ser manifestaciones no orientadas por un fin; de allí que, en el ámbito de la moral kantiana se establezca la tradicional distinción entre utilitarismo y deontologísmo, donde el utilitarismo es comprendido como una moral orientada por los fines subjetivos, mientras que el deontologismo es una alternativa moral orientada por el deber. La comunicabilidad del bien y lo bello se hacen posibles en tanto que fundadas en criterios de formalidad comunes entre entes de razón. Finalmente, el juicio sobre el bien y lo bello implica la superación de la subjetividad o la inmediatez de los placeres al construirse sobre la base humana de los juicios reflexionantes.

\section{Conclusión}

Tanto con la ética como con la estética kantiana nos situamos ante la intención de superación del relativismo y los subjetivismos, lo anterior nos ubica ante un nuevo dilema del cual el autor de las críticas, a mi parecer, ofrece una alternativa.

Si admitimos el subjetivismo o el relativismo como criterios para establecer juicios estéticos o éticos, corremos el riesgo de incurrir en un escepticismo, por el contrario, si nos situamos en un formalismo, corremos el riesgo de distanciarnos del arte y los actos morales reales, sin embargo, con la alternativa kantiana, se establece un criterio de valoración universal, que tiene su punto de partida en la razón humana y tendrá su esfera de referencia en los objetos estéticos y las acciones que se materializan.

Volviendo la obra de Nitsch y el fenómeno de su censura, esta pudiera ser objeto de análisis a partir de los parámetros establecidos por la ética y la estética kantiana y para comprensión propongo los siguientes criterios.

1. Tanto los juicios morales como estéticos que se vierten sobre la obra de Nitsch, tienen la posibilidad de ser el resultado del juicio reflexionante. 
2. Tanto la obra de Nitsch, como el acto de prohibición de su presentación, hipotéticamente ${ }^{1}$ son el resultado de un acto libre.

3. Los motivos de la moral son el juicio sobre el bien y el mal y los motivos del arte, tienen que ver con la belleza, de allí que no exista una correspondencia de fines.

4. La obra de arte es una materialización de la conciencia del artista, es decir, se materializa en un acto expuesto al público, por lo anterior, no está exento del juicio moral y, por lo tanto, de la censura.

5. El análisis sobre el caso específico de la obra de NItsch, debiera orientarse, a saber, si las razones morales por las que la obra es censurada, cumplen los criterios de una moralidad con la pretensión de universalización.

\section{Referencias}

Ballesteros, P. (2015, 6 febrero). Opinión | La «suspensión» de Hermann Nitsch en Jumex. GAS TV. http://gastv.mx/opinion-la-suspension-de-hermann-nitsch-en-jumex/

Burnett, V. (2015, 25 febrero). Museo Jumex Cancels a Hermann Nitsch Show. https://www.nytimes.com/\#publisher.

https://www.nytimes.com/2015/02/25/arts/design/museo-jumex-cancels-a-hermannnitsch-show.html

De la Colina, L. (2015). La posibilidad de un mito: especificidades del accionismo vienés. Grupo de Investigación Mitocrítica, 1(1),

https://webs.ucm.es/info/amaltea/acis/docs/20110209 de la colina \%20accionismo.pdf

Kant, I. (2003). Crítica del discernimiento (Machado Lectus $\left.n^{\circ} 2\right)$ (1. ${ }^{\mathrm{a}}$ ed.). Antonio Machado Libros.

Kant, I. (2012). Fundamentación para una metafísica de las costumbres (1. ${ }^{a}$ ed.). Alianza. Universitario.

Ortuño, G. (2015, 1 febrero). Museo Jumex suspende la exposición de Hermann Nitsch. Animal Político. https://www.animalpolitico.com/2015/01/museo-jumex-suspende-la-exposicionde-hermann-nitsch/

Plázola, J. (2007). Introducción a la estética: Historia, Teoría, Textos (Filosofía $n^{\circ}$ 19) (4. ${ }^{a}$ ed.). Universidad de Deusto.

\footnotetext{
${ }^{1}$ Afirmo que es hipotético en tanto que desconocemos las verdaderas motivaciones que llevan al artista a producir su obra y a los censores a repudiarla.
} 